Family, Cognition, Perceptions, and Reading 1

Family History, Self-Perceptions, Attitudes and Cognitive Abilities are associated with Early Adolescent Reading Skills

Elizabeth G. Conlon ${ }^{\mathrm{a}}$, Melanie J. Zimmer-Gembeck ${ }^{\mathrm{b}}$, Peter A. Creed ${ }^{\mathrm{c}}$, and Melinda Tucker ${ }^{\mathrm{a}}$ School of Psychology, and

${ }^{\mathrm{a} A p p l i e d ~ C o g n i t i v e ~ N e u r o s c i e n c e ~ R e s e a r c h ~ C e n t r e, ~}$

${ }^{b}$ Griffith Psychological Health Research Centre

${ }^{c}$ Service Industry Research Centre

Griffith University, Queensland, Australia

Address for correspondence: Dr. Elizabeth Conlon

School of Psychology

Griffith University, Gold Coast

PMB 50 Gold Coast Mail Centre, 9726. Australia

Email: e.conlon@griffith.edu.au

Fax: $\quad+61755528291$

Phone: $\quad+61755528981$ 


\begin{abstract}
This study evaluated a model of reading skills among early adolescents $(N=174)$. Measures of family history, achievement, cognitive processes and self-perceptions of abilities were obtained. Significant relationships were found between family history and children's single word reading skills, spelling, reading comprehension, orthographic processing, and children's perceived reading competence. While children with poor reading skills were five times more likely to come from a family with a history of reading difficulties, this measure did not account for additional variance in reading performance after other variables were included. Phonological, orthographic, rapid sequencing and children's perceived reading competence made significant independent contributions reading and spelling outcomes. Reading comprehension was explained by orthographic processing, non-verbal ability, children's attitudes toward reading and word identification. Thus, knowledge of family history and children's attitudes and perceptions toward reading provide important additional important information when evaluating reading skills among a normative sample of early adolescents.
\end{abstract}


Evidence has shown that phonological (e.g., Nation \& Snowling, 2004; Stanovich \& Siegel, 1994; Treiman, 2000) and orthographic (e.g., Castles \& Coltheart, 1993; Cunningham, Perry \& Stanovich, 2001) processing, as well as different forms of rapid processing of information (e.g., Eden, Stein, Wood \& Wood, 1995) have been associated with children's reading abilities. While these processes explain considerable variance in reading scores among children, they do not fully account for reading skills. Other factors that contribute to children's reading problems include biological (e.g., genetic; Tiu, Wadsworth, Olson, \& DeFries, 2004), environmental (e.g., the home literacy environment; Molfese, Modglin, \& Molfese, 2003), and self-system processes, such as children's attitudes to reading and perceptions of their own reading performance (Chapman \& Tumner, 1995). Together, the identification of children who have or will have reading problems, and our understanding of children's reading development, depend upon determining how all of these factors combine to account for success or difficulties.

One recent biobehavioural model, shown in Figure 1, illustrates the way that multiple factors may combine to explain reading outcomes (Fletcher, Foorman, Boudousquie, Barnes, Schatschneider, \& Francis, 2002). This model illustrates how the child's biology and environment act as relatively distal (i.e., indirect) factors that influence final reading outcomes, while children's cognitive functioning, perceptions, and attitudes have more direct effects. More specifically, the model predicts that biological factors have a direct impact on cognitive processing, which then directly impact reading outcomes. Similarly, environmental influences have a direct impact on self-system processes, which then directly influence reading outcomes. In this study of an unselected sample of grade 7 students $(M$ age $=12$ years $)$, multiple components of this model were tested as direct and indirect influences on word identification, 
spelling, and reading comprehension skills. Parents completed a reading history questionnaire (RHQ) and we examined whether this measure was predictive of a variety of children's processing skills or increased risk of difficulties in this normative sample. Additionally, we determined whether children as a higher risk factor of reading difficulties when they have a parent with a history of difficulties with reading.

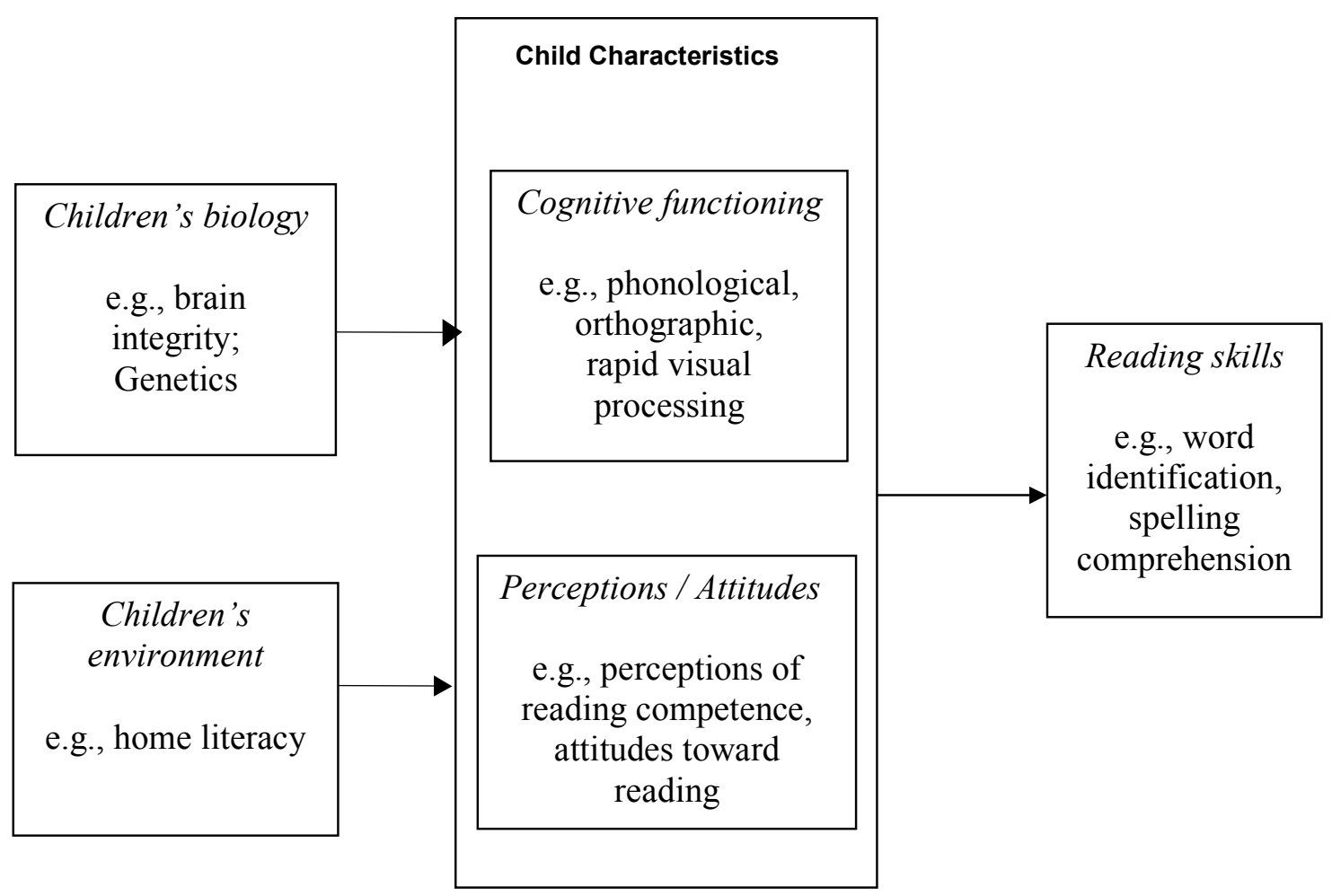

Figure 1. Modified version of a model of the antecedents of reading skills originally proposed by Fletcher et al. (2002).

Family History

There are two primary ways that the family can impact upon children's reading development. First, there is the likelihood of genetic link (DeFries, Alarcon, \& Olson, 1991). Genetic contributions to reading development are best studies with gene research, and twin or adoption studies. Second, family history can influence children's reading skills through the provision or lack of certain environmental experiences. For 
example, the home literacy environment, such as the availability of books and time has been linked to children's development of reading skills (Molfese et al., 2003). In addition, family demographic factors (e.g., socio-economic status, mothers' education level) and other environmental factors (e.g., print exposure and parental practices) have been associated with reading ability (Leslie \& Allen, 1999; Samuelsson \& Lundberg, 2003). In the current study reading-related family history was investigated as a correlate of children's reading skills. The design of the study did not allow us to determine how much of these linkages could be attributed to genetic versus environmental factors. Instead, we focus on the independent contribution of family history to children's reading skills after accounting for a range of other factors that have been shown to be predictive of reading problems.

A number of longitudinal studies have compared reading development in children from families with and without a history of reading difficulties (Elbro, Borstrom \& Petersen, 1998; Gallagher, Frith \& Snowling, 2000; Locke, Hodgson, Macaruso, Roberts, Lambrecht-Smith, \& Guttentag, 1997; Scarborough, 1989). The general finding from these studies is that by the early school years a greater proportion of children in the at-risk group are performing below expectations on literacy related activities. For example, Snowling, Gallagher, and Frith (2003) classified children as high or low risk based on a battery of psychometric tests completed by parents. They found that by age 8 , the high-risk group had significantly lower scores on measures of reading, spelling and comprehension than children in the low-risk group. More specifically $66.1 \%$ of children in the high-risk group and $13.8 \%$ of children in the low risk group experienced literacy difficulties.

Parental self-report of reading history has been found to provide a valid index of a family history of reading difficulties (Davis, Knopik, Wadsworth, \& DeFries, 2000; 
Elbro et al., 1998; Gilger, 1992; Gilger, Pennington, \& DeFries, 1991; Lefly \& Pennington, 2000). Extending the work of Finucci, Whitehouse, Isaacs and Childs (1984), Lefly and Pennington (2000) further developed and validated a measure of adult reading history that assesses school and general literacy development. The reliability and validity of this measure was good, with test-retest reliability, and discriminant validity high. In addition, using a normative cut-off, where those with a high index score $(>0.4)$ have a high probability index of dyslexia, while those with low index scores $(<0.4)$ have a low probability index, there is evidence that children with reading difficulties are more likely to come from families with a history of reading difficulties (Lefly \& Pennington). In a separate study Pennington and Lefly (2001) classified families as high or low risk based mainly on Reading History Questionnaire scores (Lefly \& Pennington, 2000). Overall, 34\% of the children in the high-risk and $6 \%$ of children in the low risk group fulfilled the criteria for reading disability by the end of a three-year longitudinal study. Children coming from a family with a positive history of reading difficulties were at 5.7 times the risk of reading difficulties than children without a positive parental history. The studies that have investigated risk have generally used younger children, so it remains unclear whether parent scores on the RHQ will add to the prediction of reading skills in a normative sample of grade 7 students.

\section{Cognitive Functioning}

Phonological processing. Further support for the biobehavioural model presented in Figure 1 derives from research that shows a strong relationship between phonological processing skills and reading skills (e.g., Compton, 2002, Snowling, 2000; Torgeson, Wagner, \& Rashotte, 1997; Vellutino, Fletcher, Snowling, \& Scanlon, 2004). Children with poor phonological processing skills have difficulty in 
segmenting words into their component sounds. In English-speaking countries, this skill is often measured by having children sound out the different components of letter strings that are phonologically regular, but are not real words (non-word decoding). It is a widely held view that children with reading disabilities have a core deficit in phonological processing (e.g., Snowling, 2000; Stanovich \& Siegel, 1994) that is independent of IQ (Fletcher et al., 1994; Olson, 2002). Additionally, children with a reading disability perform less accurately on phonological processing tasks when compared with an age-matched group of children with no reading disability showing that this is a true deficit in phonological skills rather than a developmental lag (Olson, 2002; Snowling, 2000). Direct links between language processing difficulties and specific areas of brain functioning (Pugh et al., 2001) have been established, together with a strong heritability component (Castles, Datta, Gayan, \& Olson, 1999; Gayan \& Olson, 2001).

Orthographic processing. In the English language, there are a large number of exception words. These are words that are not phonologically regular. Words such as "yacht" or "pint" are not pronounced as they are sounded using phonological rules. In addition, using phonological rules, two words may sound the same, but be spelled differently (hare, hair). Successful reading in English requires not only skilled use of phonology, but also good orthographic skills (Cunningham, Perry \& Stanovich, 2001). When children with poor reading skills are compared to age-matched controls on measures of orthographic coding, their performance does not differ, suggesting that poorer orthographic coding skills may occur as a result of a developmental lag, not a true deficit (e.g., Stanovich, Siegel, \& Gottardo, 1997). Orthographic processing skills make a significant independent contribution to the explanation of reading skills. 
Rapid visual processing. The magnocellular (M) deficit theory has pointed to the importance of a subtle sensory deficit in the neural pathway that processes temporal information as a factor in predicting poor reading skills (e.g., Livingstone, Rosen, Drislane, \& Galaburda, 1991). This theory has proven controversial with some studies providing support (e.g., Demb, Boynton, \& Heeger, 1998; Talcott et al., 2000; 2002) with others failing to consistently find effects (e.g., Amitay, Ben-Yehudah, Banai, \& Ahissar, 2002; Olson \& Datta, 2002). Hari and Renvall (2001) proposed that the visual impairment found among poor readers is explained by difficulties with attentional shifting, that is, inefficiency in disengaging attention from one stimulus, to attend to a second stimulus. From a visual perspective, this difficulty would produce problems when sequencing letter strings. Support has come from studies that have evaluated processing of rapidly presented stimulus sequences. In one study an adult dyslexic group required $700 \mathrm{~ms}$ to disengage attention from one stimulus to attend to a second (Hari, Valta, \& Uutela, (1999) and in a second study a group of 12 year old dyslexic children required at least $1400 \mathrm{~ms}$ to disengage attention from one stimulus to attend to a second, with the control group requiring significantly less time (Visser, Boden \& Giaschi, 2004). In studies that have evaluated performance on a rapid visual sequencing task, after the impact of IQ and phonological processing have been removed, significant small to moderate portions of the variance account for variance in reading skills (Conlon, Sanders, \& Zapart, 2004; Booth, Perfetti, MacWhinney, \& Hunt, 2000; Eden et al., 1995). In the present study, a measure of rapid visual sequencing was included to assess covariance with other processing measures, family history and self-system processes.

Intellectual ability. Intellectual ability has consistently been found to predict reading achievement (Maqsud, 1997; Naglieri, 2001). In the present study, intellectual 
ability was assessed to partial out this association in all analyses. The primary aims of the current study were to examine other aspects of cognitive functioning, family history and children's self-system processes as correlates of reading skills.

\section{Children's Perceptions and Attitudes about Reading}

Family history and cognitive processes alone fail to explain all of the variability in children's reading skills. Consequently, there has been a shift away from a purely cognitive interpretation to an approach that includes psychosocial factors, such as children's beliefs about the self and attitudes (Chapman \& Tumner, 2003; Fletcher et al., 2002; Lepola, Salonen, \& Vauras, 2000). Recent research has begun to evaluate the way that children think and feel about their reading skills and the impacts these perceptions have on reading skills (Bouffard, Marcoux, Vezeau, \& Bordeleau, 2003; Chapman \& Tunmer, 1995; Guay, Marsh, \& Boivin, 2003; Hamachek, 1995). It has been shown that children perform better and are more motivated to select increasingly challenging tasks when they perceive that they have the ability to accomplish a particular task (Dweck, 1999; Eccles \& Wigfield, 2002; Jacobs, Lanza, Osgood, Eccles, \& Wigfield, 2002; Skinner, Zimmer-Gembeck, \& Connell, 1998). Within the context of reading, the way children appraise their reading capabilities is expected to influence motivational aspects, such as interest in reading and reading persistence, which influences children's reading achievement (Chapman \& Tumner, 1995; Jacobs, et al., 2002).

In the present study children's perceptions of their reading competence and their attitudes toward reading were examined. The term "perceptions of reading competence" was used to refer to children's evaluations and appraisals of proficiency and skill in reading. The term "attitudes to reading" was used to refer to children's 
like or dislike of reading. As others have proposed (Chapman \& Tunmer, 1995), both components were conceptualised as forming children's overall reading self- concept. Associations between the subcomponents of reading self-concept and reading achievement have been found (Wigfield, Eccles, Arbreton, Freedman-Doan, \& Blumenfeld, 1997; Chapman \& Tunmer, 1995). By grade 4, perceptions of difficulty and competence were significantly related to reading achievement and in grade 5 attitudes towards reading also became significantly related to reading achievement. By grade 7, it would be expected that both perceptions of reading competence and attitudes toward reading would be associated with reading skills. However, it remains unclear whether these factors mediate associations between children's family history and reading skills, and whether associations between reading self-concept and reading skills would hold when a family history of reading problems, children's nonverbal abilities and processing capacities are simultaneously considered.

\section{Aims of the Present Study}

In the current study of students in grade 7 , there were two primary aims. The first aim was to examine the Adult Reading History Questionnaire (RHQ) to determine whether it was associated with aspects of children's processing and reading skills. We investigated whether a history of family reading difficulties was associated with children's (a) nonverbal ability, (b) phonological and orthographic processing, (c) rapid visual sequencing, (d) children's perceptions of their reading competence and their attitudes toward reading, (e) single word identification, (f) spelling, and (g) reading comprehension. In this general sample of school children, we also evaluated the ability of the RHQ to assess risk of reading difficulties. In most previous research, risk of reading difficulties has been evaluated using samples selected on the basis of either a family history or level of reading. If this measure is found to be predictive of 
children's reading skills, then an easy to administer scale such as this will provide additional historical information that can guide the determination of risk for reading deficits and intervention efforts.

The second aim was to test components of the biobehavioural model of reading skills (Fletcher et al., 2002). We examined reading skills as an outcome of a family history of reading difficulties and the other four factors described in the first study aim. Reading skills were assessed as lower order skills using a measure of single word identification and spelling. The ability of the model to predict scores on a reading comprehension task, a higher order skill, was also evaluated. There were two main areas of interest. First, would the RHQ still predict different reading skills when cognitive and perception and attitude variables were included in the model for the different measures of reading? Second, to what extent were children's attitudes and perceptions of reading associated with reading/spelling outcomes after the RHQ and children's cognitive functioning were considered? Given the history of interest in gender in this area, and evidence of some modest gender differences in reading skills, gender was also investigated in all analyses (Olson, 2002).

In a final analysis, groups of children with and without a family history of reading problems were identified and compared on all measured variables. The risk of a child from an unselected sample having a reading or spelling problem if they did or did not have a family history of a reading problem was obtained. The goal with this final analysis was to provide information concerning the ability of the RHQ normative index to discriminate between children at risk and children not at risk of reading difficulties. 
Method

\section{Participants}

Data were obtained for 190 children, (94 boys and 96 girls) from two local State Primary Schools in Southeast Queensland, Australia. Half of the sample came from each of the schools, which were located within $5 \mathrm{~km}$ of each other. Participants represented about $71 \%$ of students in Grade 7 in each of the schools.

Based on the eduction level of parents the schools contained a diverse group of students. The highest level of education was grade 10 for $31 \%$ of mothers, with $18 \%$ completing grade $12,33 \%$ completing a technical course or apprenticeship, and the remaining $18 \%$ reporting completion of a university course. A similar pattern of education was found among the fathers. No significant relationships were found between mother's education level and children's reading level or parent score on the RHQ. The average age of child participants was 11.9 years, with ages ranging from 11 to 13 years. The children were all in grade 7 (the final year of primary school in Queensland). A biological parent of 174 of these children also participated by completing demographic information and the RHQ. If a parent experienced some reading difficulties it was requested that the parent experienced some reading difficulties should respond to the questionnaire, if possible. All but six of the families reported English as the first language. (Analysis conducted with these families removed from the sample failed to produce any change in the results so all were retained.)

Apparatus and Measures

Family reading history. The Adult Reading History Questionnaire (RHQ; Lefly \& Pennington, 2000) was used to assess a history of parental reading problems and other reading problems in the family. The questionnaire was completed in the home 
by 165 of the parents, with nine completing the scale over the phone with a trained assistant. The questionnaire contained 25 items, with some addressing early reading history (e.g., "Did you have difficulty learning to spell in Primary School?") and others current literacy practices (e.g., "How many books do you read each year?”). The response options usually ranged from 0 (no difficulty) to 4 (a great real of difficulty). With items that asked questions about current reading, a number category was given. The questionnaire does not identify the cause of the reported reading difficulties. Reported reliability of the scale has been high, $\alpha=.90$ (Lefly $\&$ Pennington), and was similarly high in the current study, $\alpha=.88$. In initial investigations of this scale, the normative index score was independent of mother's reported level of education, so mother's level of education was not included in further analyses.

Non-verbal ability. The Ravens Standard Progressive Matrices was used to measure nonverbal ability (Raven, Raven, \& Court, 2000). This is a standardised test of non-verbal reasoning. Participants selected the correct missing part of a presented pattern. There are 60 trials of increasing difficulty. In this study a 20-minute timed group administration was used. Coefficient alpha for this test has been reported to be adequate, $\alpha=.71$ (Gregory, 2000).

Orthographic processing. A Pseudohomophone Discrimination Task (Olson, Forsberg, Wise, \& Rack 1994) was used to assess orthographic processing. The participant's task was to determine which of two words (e.g. "pleese" or "please") presented on a single trial was spelt correctly. This task controls for both environmental influences (Castles et al., 1999) and the phonological sounds of the words and was presented as a paper and pencil test, where children circled the word in each pair that they believed was correct. There were two practice trials followed by 19 
test trials. These 19 trials were selected from the 80 trials originally used by Olson et al. (1994). Stimulus pairs were selected based on item difficulty that was evaluated in pilot testing. Number correct was the measure of accuracy. Because of the skew of this measure, scores were reversed and a square root transformation was used. Hence, high scores reflect more difficulties.

Phonological processing. Children's phonological processing ability was assessed using an adaptation of the Phonological Choice Task (i.e., a silent decoding measure; Olson et al., 1994). On each trial, three non-words were presented. Children silently sounded each non-word (e.g., "goote“, "mooze”, "chooze”) and then circled the non-word that sounded like a real word. There were two practice trials followed by 19 test trials, presented in paper and pencil format. Trials used were selected based on item difficulty determined in pilot testing from the 60 used in the original test. The number correct was the measure of accuracy obtained. Because of the skew of this measure, scores were reversed and a square root transformation was used. Hence, high scores reflect more difficulties.

Rapid visual sequencing. Children's rapid visual processing skills were assessed with a Rapid Visual Sequencing task. In this task, children were presented with a series of trials where stimulus dots were sequentially presented in the same location on a computer screen. The task was to count the number of stimuli presented in a single trial. Duration of each stimulus dot was $40 \mathrm{msec}$. The interstimulus interval (ISI) between stimulus presentations ranged from 200 to $280 \mathrm{msec}$. The ISI was varied so that children could not rhythmically count the number of stimuli presented. On any one trial the number of stimuli presented ranged from 1 to 8 , with 6 trials per stimulus condition. Children were required to inform the experimenter of how many stimuli were presented on a single trial. There were 16 practice trials. These were 
followed by the test trials. The stimulus dot was of low luminance, presented on a grey background. Viewing distance was $57 \mathrm{~cm}$ from the computer screen. Initial investigation of these data found a floor effect when larger number of stimuli was sequentially presented. As a result the three stimulus sequence, which was normally distributed was used in all analyses for this project ${ }^{1}$.

Attitude to reading and perceptions of reading competence. A scale developed by Chapman and Tumner (1995) to assess reading self-perceptions and attitudes was used. This is a 30-item scale with response options ranging from 1 (never) to 5 (always). Items were designed to assess three components of reading competence, namely, difficulty with reading (e.g., "Do you make lots of mistakes in reading?”), perceptions of reading competence (e.g., "Do you think you read well?"), and attitude to reading (“Is it fun for you to read books?"). In a previous study using younger children factor analysis of the responses of 444 children produced evidence of the three independent dimensions (Chapman \& Tumner). As the participants in the present study were slightly older by two grade levels, factor analysis was conducted prior to forming the composite scale scores. Two factors were deemed best. The first factor was labelled "attitudes to reading" with similar item loadings as in the earlier study. The second factor was labelled "perception of reading competence." Items that loaded on this second factor were those from the original subscales of reading difficulty and perceptions of reading competence. Hence, perceptions of competence and difficulty seemed to reflect one underlying construct in this older age sample ${ }^{2}$.

\footnotetext{
1 The full analyses using the rapid sequencing task is currently being written up. Further information on these data can be obtained from the authors.

${ }^{2}$ Further information on the analysis of this scale is available from the authors
} 
Internal consistency for both subscales was high, with attitudes to reading $\alpha=.93$, and perceptions of reading competence $\alpha=.89$.

Word identification and spelling. Single word reading and spelling were evaluated using the Wide Range Achievement Test (WRAT-3, Wilkinson, 1993). In the single word identification component there are 42 items of increasing difficulty. This test is conducted individually, with administration ceasing following 10 consecutive errors. Grade levels and standard scores can be computed for five through to 74 year olds. The spelling component of the WRAT-3 was also used. This component required participants to spell 40 consecutive words that were dictated to participants. In this study, this test was conducted in a group, but scored in the standard manner. The WRAT-3 is widely used and the reliability of these tests has been reported to be high.

Reading comprehension. This was the Viewing and Reading component of the Queensland CORE Skills Test completed by all students in Year 7. Children had to interpret the meaning of different forms of text.

\section{Procedure}

Following approval by the Human Research Ethics Committee of Griffith University and Education Queensland, two schools in an urban area of Queensland, Australia were approached and participated in the study. Following parental consent, data were obtained from children in three sessions in their normal school environments. Two of these were group sessions in the children's regular classroom. In the first of these measures of spelling, non-verbal ability, orthographic processing, and phonological processing were obtained. In the second, the measures of children's perceptions and attitudes toward reading were obtained. In each group testing session there were three research assistants available to children for any queries. In a third, 
individual session, all children completed the rapid visual sequencing task and the word identification component of the WRAT-3.

The CORE skills test was undertaken with teacher supervision. The results of this test were made available to the research team based upon parental permission.

\section{Results}

Initial investigation of the measures showed some negative skew in the measures of orthographic and phonological processing. This was corrected with a reflect and square-root transformation of the data, resulting in negative linear relationships between this and other measures of word reading skills. Three extreme scores were found on the spelling measure. These 3 children had standardized spelling scores below 60 and had reading scores at least 30 points higher. This may reflect their lack of engagement in the group spelling measurement task. One child was removed from the comprehension measure due to an extreme positive score. Each of these scores was removed from the data analysis for this study. All other variables were normally distributed.

\section{Correlations}

Correlates of the Adult Reading History Questionnaire (RHQ). Correlations among all measures are shown in Table 1. Significant negative relationships were found between family history of reading difficulty scores and children's single word reading, spelling, comprehension, perceptions of their reading competence, and attitudes to reading. These findings show that relatively more history of family reading problems is linked to more difficulties with reading and spelling, and lower perceptions of competence and less interest in reading. There was also a significant positive association between family reading history and orthographic processing, indicating that a relatively higher family history of reading difficulties was predictive 
of lower orthographic processing ability. No significant relationships were found between the family reading history and phonological processing, rapid visual sequencing or non-verbal ability.

Correlations between child measures. As expected and proposed by Fletcher et al (2002), correlations showed that a family history of reading problems, as well as children's cognitive functioning, perceptions and attitudes, are all significantly associated with word identification, spelling ability and reading comprehension. Significant associations were found between nonverbal ability and all reading and cognitive measures, and between children's perceptions of competence and the reading and cognitive measures. Weaker, but still significant, relationships were also found between children's attitudes to reading and the reading and cognitive measures. Predicting Word Identification Skills

A hierarchical multiple regression analysis $(N=172)$ was conducted with gender, family reading history (RHQ) and children's nonverbal skills entered at Step 1 (see Table 2). At Step 2, phonological, orthographic and rapid visual processing skills were entered. At Step 3, perceptions of reading competence and attitudes to reading were entered. Assumptions of the multiple regression analyses were examined and no problems were found. 
Table 1

Bivariate Correlations between Variables

\begin{tabular}{|c|c|c|c|c|c|c|c|c|c|c|}
\hline \multicolumn{2}{|c|}{ Variables } & 1 & 2 & 3 & 4 & 5 & 6 & 7 & 8 & 9 \\
\hline 1 & Parent Reading History & -- & & & & & & & & \\
\hline 2 & Nonverbal ability & -.03 & & & & & & & & \\
\hline 3 & Rapid visual processing & -.12 & $.21^{* *}$ & & & & & & & \\
\hline 4 & Attitude to reading & $-.19 *$ & .08 & .00 & -- & & & & & \\
\hline 5 & Reading competence & $-.23 * *$ & $.18^{*}$ & $.28 * * *$ & $.41 * * *$ & -- & & & & \\
\hline 6 & Phonological skill $^{\mathrm{a}}$ & .12 & $-.47 * * *$ & $-.15^{*}$ & $-.18^{*}$ & $-.44 * * *$ & -- & & & \\
\hline 7 & Orthographic skill $^{\text {a }}$ & $.16^{*}$ & $-.43 * * *$ & $-.14^{*}$ & $-.25 * * *$ & $-.39 * * *$ & $.42 * * *$ & -- & & \\
\hline 8 & Word identification & $-.18 *$ & $.35 * * *$ & $.35 * * *$ & $.26^{* * *}$ & $.58 * * *$ & $-.53 * * *$ & $-.40 * * *$ & -- & \\
\hline 9 & Spelling & $-.21 * *$ & $.45^{* * *}$ & $.32 * * *$ & $.29 * * *$ & $.62 * * *$ & $-.59 * * *$ & $.56 * * *$ & $.74 * * *$ & -- \\
\hline 10 & Reading comprehension & $-.23 * *$ & $.47 * * *$ & $.29 * * *$ & $.37 * * *$ & $.53 * * *$ & $-.49 * * *$ & $-.51 * * *$ & $.56^{* * *}$ & $.58 * * *$ \\
\hline
\end{tabular}

Note. $N$ ranged from 163 to 190.

${ }^{*} p<.05 . * * p<.01 .{ }^{* * *} p<0.001$.

${ }^{\mathrm{a}} \mathrm{S}$ cores were reversed and a square root transformation used. 
Table 2

Results of Hierarchical Multiple Regression Analysis Regressing Word Identification Skills on Measures of Children's Abilities, Processing Skills, Perceptions and Attitudes. $N=172$

\begin{tabular}{|c|c|c|c|c|c|c|}
\hline \multirow[b]{2}{*}{ Variables } & \multirow[b]{2}{*}{$B$} & \multirow[b]{2}{*}{$S E(B)$} & \multicolumn{2}{|c|}{$95 \% C I(B)$} & \multirow[b]{2}{*}{$\beta$} & \multirow[b]{2}{*}{$s r^{2}$} \\
\hline & & & Lower & Upper & & \\
\hline \multicolumn{7}{|l|}{ Step 1} \\
\hline Gender & -3.23 & 2.29 & -7.75 & 1.28 & -.10 & 1.17 \\
\hline Parent Reading History & -22.17 & 8.84 & -39.62 & -4.72 & $-.18 *$ & 3.61 \\
\hline Nonverbal ability & .40 & .08 & 0.24 & 0.55 & $.36^{* * *}$ & 13.10 \\
\hline \multicolumn{7}{|l|}{ Step 2} \\
\hline Gender & -3.51 & 1.96 & -7.37 & 0.36 & -.11 & 1.90 \\
\hline Parent Reading History & -10.38 & 7.73 & -25.64 & 4.89 & -.08 & 1.08 \\
\hline Nonverbal ability & .08 & .08 & -0.08 & 0.24 & .07 & 0.01 \\
\hline Phonological skill $^{\mathrm{a}}$ & -7.82 & 1.53 & -10.83 & -4.80 & $-.36 * * *$ & 13.69 \\
\hline Orthographic skill $^{\text {a }}$ & -5.90 & 2.46 & -10.76 & -1.04 & $-.17 *$ & 3.39 \\
\hline Rapid visual processing & 2.52 & .60 & 1.35 & 3.70 & $.27 * * *$ & 9.80 \\
\hline \multicolumn{7}{|l|}{ Step 3} \\
\hline Gender & -2.41 & 1.85 & -6.05 & 1.24 & -.07 & 1.02 \\
\hline Parent Reading History & -4.20 & 7.36 & -18.73 & 10.34 & -.03 & 0.00 \\
\hline Nonverbal ability & .13 & .08 & -0.02 & 0.28 & .12 & 1.85 \\
\hline Phonological skill $^{\mathrm{a}}$ & -5.30 & 1.52 & -8.30 & -2.30 & $-.24 * *$ & 6.92 \\
\hline Orthographic skill $^{\mathrm{a}}$ & -2.70 & 2.40 & -7.42 & 2.04 & -.08 & 0.01 \\
\hline Rapid visual processing & 1.91 & .58 & 0.77 & 3.04 & $.20 * *$ & 6.30 \\
\hline Reading competence & 8.28 & 1.84 & 4.65 & 11.91 & $.33 * * *$ & 11.09 \\
\hline Attitude to reading & .68 & 1.03 & -1.37 & 2.72 & .04 & 0.00 \\
\hline
\end{tabular}

Note: $R^{2}$ at Step $1=.17\left(\triangle R^{2}=.17\right), R^{2}$ at Step $2=.40\left(\triangle R^{2}=.23\right)$,

$R^{2}$ at Step $3=.48\left(\triangle R^{2}=.08\right)$.

${ }^{*} p<.05 . * * p<.01 . * * * p<.001$.

${ }^{a}$ Scores were reversed and a square root transformation used. Higher scores indicate more difficulty. 
As can be seen in Table 2, 17\% of the variance in word identification was accounted for by the combination of gender, family reading history, and nonverbal ability in Step $1, \mathrm{~F}(3,168)=11.1, p<.001$. Family history, $\beta=-.18, p<.05$, and nonverbal ability, $\beta=.36, p<.001$, were significantly associated with word identification skills, while no association between gender and word identification was found. Specifically, children with more of a family history of reading problems and lower abilities had relatively poorer word identification skills.

The combination of cognitive variables entered in Step 2 accounted for an additional and significant $23 \%$ of the variance in word identification skills, $\mathrm{F}_{\text {chg }}(3$, $165)=21.4, p<.001$. All measures were significantly associated with word identification skills: phonological processing skills $\beta=-.36, p<.001$; orthographic processing $\beta=-.17, p<.05$; rapid visual processing $\beta=.27, p<.001$. Recall that orthographic and phonological processing measures were reversed, so children with poorer orthographic and phonological processing skills (i.e., higher processing scores) had lower word identification skills, while those who more accurately processed rapidly presented visual information had better word identification skills. Consistent with the model presented in Figure 1, the addition of the three variables at Step 2 reduced the beta weights of family reading history and non-verbal ability to near zero, indicating mediation of the distal variables by phonological, orthographic and rapid visual processing.

At Step 3, a further $8 \%$ of the variance was explained by children's perceptions of reading competence and attitude to reading, $\mathrm{F}_{\text {chg }}(2,163)=12.8, p<.001$. Children's perceptions of reading competence was significantly associated with word identification skills, $\beta=.33, p<.001$, but there was no independent association between children's attitude toward reading and their word identification skills. The 
addition of reading competence reduced the effect of orthographic processing to near zero, and reduced the effect of phonological and rapid visual processing.

In sum, $48 \%$ of the variance in word identification skills was accounted for by the independent variables. In the final inspection of the regression coefficients shown in Table 2, children's perceptions of reading competence had the strongest association with word identification skills, followed by phonological processing and rapid visual processing. This may indicate that, as shown in Figure 1, children's cognitive processing abilities (phonological and rapid visual processing) and perceptions of reading competence mediated the impact of these measures on word identification. Predicting Spelling Skills

An identical analysis to that conducted for word identification skills was used to examine correlates of children's spelling skills $(N=169)$. All assumptions of the multiple regression analysis were met.

As can be seen in Table 3, 21\% of the variance in spelling skills was accounted for by the combination of gender, family history, and nonverbal ability entered in Step 1 of the model, $F(3,165)=14.9, p<.001$. Findings were similar to those with word identification skills, with family history, $\beta=-.20, p<.01$, and nonverbal ability, $\beta=$ $.41, p<.001$, significantly associated, but no significant association between gender and spelling skills. 
Table 3

Results of Hierarchical Multiple Regression Analysis Regressing Spelling Skills on

Measures of Children's Abilities, Processing Skills, Perceptions and Attitudes $N=169$

\begin{tabular}{|c|c|c|c|c|c|c|}
\hline \multirow[b]{2}{*}{ Variables } & \multirow[b]{2}{*}{$B$} & \multirow[b]{2}{*}{$S E(B)$} & \multicolumn{2}{|c|}{$95 \% C I(B)$} & \multirow[b]{2}{*}{$\beta$} & \multirow[b]{2}{*}{$s r^{2}$} \\
\hline & & & Lower & Upper & & \\
\hline \multicolumn{7}{|l|}{ Step 1} \\
\hline Gender & -.28 & 1.75 & -3.66 & 3.11 & -.01 & 0.00 \\
\hline Parent Reading History & -18.69 & 6.58 & -31.67 & -5.70 & $-.20^{* *}$ & 4.67 \\
\hline Nonverbal ability & .36 & .06 & 0.24 & 0.47 & $.41 * * *$ & 17.89 \\
\hline \multicolumn{7}{|l|}{ Step 2} \\
\hline Gender & -.47 & 1.39 & -3.21 & 0.74 & -.02 & 0.00 \\
\hline Parent Reading History & -8.53 & 5.43 & -19.25 & 2.19 & -.09 & 0.02 \\
\hline Nonverbal ability & .08 & .06 & -0.03 & 0.19 & .09 & 0.01 \\
\hline Phonological skill $^{\mathrm{a}}$ & -6.36 & 1.09 & -8.50 & -4.21 & $-.38 * * *$ & 17.10 \\
\hline Orthographic skill $^{\mathrm{a}}$ & -7.76 & 1.73 & -11.17 & -4.34 & $-.29 * * *$ & 11.02 \\
\hline Rapid visual processing & 1.43 & .42 & 0.59 & 2.26 & $.20 * *$ & 6.55 \\
\hline \multicolumn{7}{|l|}{ Step 3} \\
\hline Gender & .55 & 1.25 & -1.91 & 3.01 & .02 & 0.00 \\
\hline Parent Reading History & -3.18 & 4.92 & -12.90 & 6.54 & -.03 & 0.00 \\
\hline Nonverbal ability & -.13 & .05 & 0.03 & 0.23 & $.15^{*}$ & 3.84 \\
\hline Phonological skill $^{\mathrm{a}}$ & -4.15 & 1.03 & -6.18 & -2.12 & $-.25 * * *$ & 9.24 \\
\hline Orthographic skill $^{\mathrm{a}}$ & -4.86 & 1.61 & -8.03 & -1.69 & $-.18 * *$ & 5.43 \\
\hline Rapid visual processing & .89 & .39 & 0.12 & 1.66 & $.12 *$ & 3.13 \\
\hline Reading competence & 7.33 & 1.25 & 4.86 & 9.79 & $.38 * * *$ & 17.72 \\
\hline Attitude to reading & .60 & .70 & -0.78 & 1.98 & .05 & 0.01 \\
\hline
\end{tabular}

Note: $R^{2}$ at Step $1=.21\left(\triangle R^{2}=.21\right), R^{2}$ at Step $2=.50\left(\triangle R^{2}=.29\right)$,

$R^{2}$ at Step $3=.60\left(\triangle R^{2}=.11\right)$.

$* p<.05 . * * p<.01 . * * * p<.001$.

${ }^{a}$ Scores were reversed and a square root transformation used. Higher scores indicate more difficulty. 
The combination of cognitive variables entered in Step 2 accounted for an additional and significant $29 \%$ of the variance in spelling skills, $\mathrm{F}_{\text {chg }}(3,162)=30.3, p$ $<.001$. All measures were significantly associated with spelling skills, phonological processing skills $\beta=-.38, p<.001$; orthographic processing $\beta=-.29, p<.05$; rapid visual processing $\beta=.20, p<.01$. The same reduction in effect for family reading history and non-verbal ability was found for this analysis, as that found for word identification above. At Step 3, a further $11 \%$ of the variance was explained by measures of children's perceptions and attitudes to reading, $\mathrm{F}_{\text {chg }}(2,160)=21.9, p<$ .001. As was found with word identification skills, children's perceptions of reading competence was significantly associated with spelling skills, $\beta=.38, p<.001$, but there was no independent association between children's attitude toward reading and their spelling skills. Perceptions of reading competence again, reduced the effect of phonological, orthographic and rapid visual processing.

In sum, $60 \%$ of the variance in spelling skills was accounted for by all the independent variables included in this model. In the final inspection of the standardized regression coefficients shown in Table 3, the children's perceptions of reading competence had the strongest association with spelling skills, followed by phonological and orthographic processing. In Step 3, family reading history was no longer significantly associated with spelling skills. Again, this may indicate that, as shown in Figure 1, children's cognitive processing abilities (phonological, orthographic, and rapid visual processing) and perceptions of reading competence mediated the impact of these measures on spelling ability. Nonverbal ability remained significantly associated with spelling ability in Step 3. 


\section{Predicting Reading Comprehension}

Comprehension is a higher-level measure of reading achievement that relies on good word recognition skills. To examine the ability of model components to predict reading comprehension, a hierarchical regression analyses was conducted. The dependent variable in this model was reading comprehension as measured by the Queensland CORE Skills Test, which was available for 159 of the participants. Steps 1, 2 and 3 in these models were the same as those used in the analysis of word identification and spelling skills.

At Step 4, single word reading and spelling skills were entered. This step was taken to determine the amount of variance in the higher order skill of reading comprehension that could be accounted for by these lower order skills, and whether other components of the model remained significantly associated with reading comprehension once the lower order skills of word identification and spelling were accounted for. Although these data are cross-sectional and pathways can only be suggestive, we expected that this information would provide an indication of potential pathways from family history and child characteristics to reading comprehension scores as mediated via the children's lower order abilities of word identification and spelling.

After inspection of the data, one child with an unusually high performance score on the reading comprehension test was removed from the analysis, leaving 158 participants. The results are displayed in Table 4. At Step 1, 25\% of the variance in reading comprehension was accounted for by the combination of gender, family reading history, and children's nonverbal ability, $\mathrm{F}(3,154)=16.7, p<.001$. Family history, $\beta=-.21, p<.01$, and nonverbal ability, $\beta=.44, p<.001$, were significantly associated with reading comprehension scores, but no significant association between gender and reading comprehension was found. 
Family, Cognition, Perceptions, and Reading 26

Table 4

Results of Hierarchical Multiple Regression Analysis Regressing Reading Comprehension CORE Skills Test Scores on Measures of Children's Abilities, Processing Skills, Perceptions Attitudes and Lower Order Reading/Spelling Skills $N=158$

\begin{tabular}{|c|c|c|c|c|c|c|}
\hline \multirow[b]{2}{*}{ Variables } & \multirow[b]{2}{*}{$B$} & \multirow[b]{2}{*}{$S E(B)$} & \multicolumn{2}{|c|}{$95 \% C I(B)$} & \multirow[b]{2}{*}{$\beta$} & \multirow[b]{2}{*}{$s r^{2}$} \\
\hline & & & Lower & Upper & & \\
\hline \multicolumn{7}{|l|}{ Step 1} \\
\hline Gender & 1.46 & 1.16 & -12.69 & 15.61 & .01 & 0.00 \\
\hline Parent Reading History & -82.04 & 27.20 & -135.78 & -28.30 & $-.21 * *$ & 5.57 \\
\hline Nonverbal ability & 1.59 & .25 & 1.09 & 2.10 & $.44 * * *$ & 20.34 \\
\hline \multicolumn{7}{|l|}{ Step 2} \\
\hline Gender & .53 & 6.25 & -11.82 & 12.88 & .01 & 0.00 \\
\hline Parent Reading History & -42.44 & 24.42 & -90.68 & 5.80 & -.11 & 0.06 \\
\hline Nonverbal ability & .70 & .25 & 0.20 & 1.21 & $.19 * *$ & 4.80 \\
\hline Phonological skill $^{\mathrm{a}}$ & -19.36 & 4.86 & -28.97 & -9.75 & $-.28 * * *$ & 9.49 \\
\hline Orthographic skill $^{\mathrm{a}}$ & -31.32 & 7.72 & -46.56 & -16.08 & $-.28 * * *$ & 9.86 \\
\hline Rapid visual processing & 4.83 & 1.91 & 1.06 & 8.60 & $.16^{*}$ & 4.08 \\
\hline \multicolumn{7}{|l|}{ Step 3} \\
\hline Gender & 2.93 & 5.97 & -8.87 & 14.71 & .03 & 0.00 \\
\hline Parent Reading History & -24.56 & 23.47 & -70.93 & 21.82 & -.06 & 0.01 \\
\hline Nonverbal ability & .84 & .24 & 0.36 & 1.32 & $.23^{* *}$ & 7.45 \\
\hline Phonological skill $^{\mathrm{a}}$ & -13.82 & 4.87 & -23.46 & -4.19 & $-.20 * *$ & 5.11 \\
\hline Orthographic skill $^{\mathrm{a}}$ & -22.06 & 7.60 & -37.08 & -7.03 & $-.20 * *$ & 5.34 \\
\hline Rapid visual processing & 3.67 & 1.87 & -0.03 & 7.36 & .12 & 2.56 \\
\hline Reading competence & 16.60 & 6.00 & 4.75 & 28.45 & $.21 * *$ & 4.88 \\
\hline Attitude to reading & 7.09 & 3.35 & 0.47 & 13.70 & $.14^{*}$ & 2.92 \\
\hline \multicolumn{7}{|l|}{ Step 4} \\
\hline Gender & 5.00 & 5.91 & -6.68 & 16.67 & .05 & 0.00 \\
\hline Parent Reading History & -22.00 & 23.08 & -67.61 & 23.61 & -.06 & 0.01 \\
\hline Nonverbal ability & .77 & .24 & 0.29 & 1.25 & $.21 * *$ & 6.40 \\
\hline Phonological skill $^{\mathrm{a}}$ & -10.43 & 5.08 & -20.47 & -0.39 & $-.15^{*}$ & 2.79 \\
\hline Orthographic skill $^{\mathrm{a}}$ & -20.33 & 7.64 & -35.44 & -5.22 & $-.18 * *$ & 4.58 \\
\hline Rapid visual processing & 2.51 & 1.89 & -1.22 & 6.24 & .08 & 0.01 \\
\hline Reading competence & 11.37 & 6.58 & -1.63 & 24.37 & .14 & 1.99 \\
\hline Attitude to reading & 6.87 & 3.29 & 0.37 & 13.37 & $.13^{*}$ & 2.89 \\
\hline Spelling & -1.55 & .42 & -0.99 & 0.68 & -.04 & 0.00 \\
\hline Word Identification & .74 & .28 & 0.18 & 1.30 & $.24 *$ & 4.45 \\
\hline
\end{tabular}

Note: $R^{2}$ at Step $1=.25\left(\triangle R^{2}=.25\right), R^{2}$ at Step $2=.44\left(\triangle R^{2}=.19\right)$,

$R^{2}$ at Step $3=.50\left(\triangle R^{2}=.06\right), R^{2}$ at Step $4=.53\left(\triangle R^{2}=.03\right)$.

$* p<.05 . * * p<.01 . * * * p<.001$.

${ }^{\mathrm{a}} \mathrm{S}$ cores were reversed and a square root transformation used. Higher scores indicate more difficulty. 
At Step 2, a further $19 \%$ of the variance was accounted for and all three entered variables were significantly associated with reading comprehension, $F_{\text {chg }}(3,151)=$ $17.14, p<.001$, phonological processing $\beta=-.28, p<.001$, orthographic processing $\beta$ $=-.28, p<.001$, rapid visual processing, $\beta=.16, p<.05$. At Step 3, children's perceptions of reading competence and attitudes to reading accounted for an additional $6 \%$ of the variance in reading comprehension skills, $\mathrm{F}_{\text {chg }}(2,149)=9.75, p<$ .001 . Both perceptions of reading competence, $\beta=.21, p<.001$, and attitudes to reading, $\beta=.14, p<.05$, were significantly and positively associated with reading comprehension.

At the final step, when word identification and spelling scores were added to the model, a further $3 \%$ of the variance in reading comprehension scores was accounted for, $\mathrm{F}_{\text {chg }}(2,147)=3.97, p<.05$. Only word identification had a significant association with reading comprehension scores on the CORE skills test, $\beta=.24, p<.05$. Even after the entry of word identification and spelling skills in Step 4, children's nonverbal ability, orthographic and phonological processing scores, and attitude to reading made unique and significant contributions to the prediction of reading comprehension. Specifically, children with higher nonverbal ability, better orthographic and phonological processing abilities, and more positive attitudes toward reading had relatively higher scores on the reading comprehension CORE skills test - a major marker of the reading progress of children in school.

Comparisons of Children in Families With and Without a History of Reading Difficulties

Two groups were next formed based on the recommendation of Lefly and Pennington (2000) that an index score on the RHQ of 0.40 or greater be the cut-off for significant impact of a history of reading difficulties in the family. A RHQ index 
score below 0.40 suggests that parents do not have any difficulties with reading.

There were 20 children identified as living in a family with an RHQ of .40 or above. This group was labelled the "parent at risk group." The remaining group was labelled the "parent not at risk group". A series of independent group t-tests were conducted to compared children's reading and spelling skills if they lived in a family with a high or low RHQ score (see Table 5). Children in the group, where parent's obtained high scores on the RHQ had significantly lower word identification skills. They also had lower spelling skills and lower reading comprehension CORE Skills Test scores and reading competence. No significant between groups effects were found for nonverbal abilities, cognitive processing skills and attitudes to reading (see Table 5).

Table 5

Comparisons of Children from Families With and Without a History of Reading Problems

\begin{tabular}{|c|c|c|c|c|c|c|}
\hline \multirow[b]{2}{*}{ Variables } & \multicolumn{2}{|c|}{$\begin{array}{c}\text { With Family } \\
\text { History }\end{array}$} & \multicolumn{2}{|c|}{$\begin{array}{c}\text { Without Family } \\
\text { History }\end{array}$} & \multirow[b]{2}{*}{$t$} & \multirow[b]{2}{*}{$\begin{array}{l}\text { effect } \\
\text { size }(d)\end{array}$} \\
\hline & $M$ & $S D$ & $M$ & $S D$ & & \\
\hline Nonverbal ability & 101.95 & 14.73 & 100.05 & 14.54 & 0.55 & .13 \\
\hline Phonological skill $^{\mathrm{a}}$ & 2.16 & 0.72 & 1.89 & 0.74 & 0.64 & .34 \\
\hline Orthographic skill ${ }^{\mathrm{a}}$ & 1.89 & 0.50 & 1.71 & 0.45 & 0.51 & .44 \\
\hline Rapid visual processing & 23.50 & 7.57 & 23.94 & 7.87 & 0.24 & .05 \\
\hline Reading competence & 3.25 & 0.72 & 3.68 & 0.61 & $2.90 * *$ & .69 \\
\hline Attitude to reading & 2.85 & 1.02 & 3.27 & 0.97 & 1.84 & .43 \\
\hline Word identification & 99.15 & 21.26 & 111.42 & 14.87 & $3.29 * *$ & .78 \\
\hline Spelling & 95.90 & 14.21 & 104.59 & 12.11 & $2.95^{* *}$ & .70 \\
\hline Reading comprehension & 670.10 & 44.86 & 704.24 & 51.24 & $2.83 * *$ & .69 \\
\hline
\end{tabular}

Note. With Family history $n=20$. Without family history $n$ ranged from 144 to 154 .

$* * p<.01$.

${ }^{\mathrm{a}}$ Scores were reversed and a square root transformation used. Higher scores indicate more difficulty. 
Finally, children were grouped on the basis of word identification scores on the Wide Range Achievement Test (Wilkinson, 1993). Those with a standard single word reading score of 90 or below were classified as "poor readers." Other children were classified into a group labelled "good readers." Using this method, 32 (16.8\%) poor readers were identified. A risk analysis revealed that a child coming from a family with a positive history of reading difficulties was significantly more likely to experience reading difficulties than a child coming from a family without a positive history of reading difficulties, $\chi^{2}(1)=9.8, p<.01$. Calculating the odds that a child with a family history would be a poor reader compared to the odds that a child without a family history would be a poor reader (an odds ratio), a child coming from a family with a history of reading difficulties was, on average, 5.2 times $(95 \%$ confidence interval $1.9-14.0$ ) more likely to have a reading difficulty than a child from a family with no history of reading difficulties.

When this analysis was repeated using standardized spelling scores, 36 (19.7\%) children from the sample scored below and were classified as "poor spellers." Children with a family history of reading difficulties were more likely to be poor spellers than other children, $\chi^{2}(1)=6.2, p<.05$. The odds ratio calculation showed that a child with a family history of a reading difficulty was, on average, 3.7 times (95\% confidence interval 1.4 to 10.4 ) more likely to be a poor speller than a child who came from a family with no history of reading difficulties.

\section{Discussion}

Few past studies with unselected samples of children have included the range of family history, cognitive functioning, self-system variables and reading-related outcomes included in the current study. Taking this multivariable approach has added much to our understanding of the factors that contribute to reading performance in a general sample of early adolescents. In particular, we found the benefit of obtaining a 
measure of family history of reading behaviour contributed significantly to the explanation of reading skills, supporting the first aim of the study. While phonological processing tended to be the largest unique contributor to reading scores, rapid visual sequencing, orthographic processing and children's perceptions of their own reading competence also contributed to outcome.

\section{Adult Reading History Questionnaire as an indicator of risk.}

The results of this study show that reading outcome for children is influenced by retrospective reports of parent's reading experience and parents' current reading habits. Parent scores on the RHQ were directly related to poorer orthographic processing and children's less positive perceptions of their competence and ease with reading, but not phonological, non-verbal processing or rapid visual sequencing. When used as a predictor of word identification, spelling and comprehension, the effect size $(\beta)$ for the parent RHQ was similar for each of the three analyses showing that reports of family history provide a measure of increased risk of poorer performance in 12 year olds from a non-selected sample.

A number of previous studies have demonstrated that exposure to text using the author or title checklists is predictive of children's word recognition, spelling and comprehension scores (Cipielewski \& Stanovich, 1992; Cunningham \& Stanovich, 1997; McBride-Chang, Manis, Seidenberg, Custodia, \& Doi, 1993; Stanovich \& West, 1989). McBride-Chang et al., when evaluating exposure to print in groups of reading disabled and skilled readers, of a similar average age to the sample used in this study, found a significant relationship between the orthographic coding task and the Titles Recognition Checklist. This is consistent with the relationship found in this study between the RHQ index score and orthographic processing in children.

In this study, when different aspects of cognitive processing were added to the model, the RHQ index score failed to make a significant independent contribution to 
the explanation. The strongest impact of the RHQ index score was found in the odds analysis, with children with poorer word identification performance five times more likely to come from a family with an index score on the RHQ of 0.4 or greater. This is a lower ratio than that reported previously, however, neither children nor their families were selected on the basis of poor reading skills, or a prior family history of dyslexia. In the current study, children in homes where there was a history of reading difficulty, on average, read, spelled and comprehended more poorly than those who came from families without a history of difficulty and had lower perceptions of their competencies. Children in families with a history of reading difficulties did not differ from other children in nonverbal ability, processing skills or attitudes toward reading. The importance of prior history was clearly demonstrated in this analysis. In terms of assessment with children of this age, this is an important indicator of risk, although in the prediction model it was subsumed by other performance variables. These analyses demonstrated that family history was a distal indicator of reading difficulties, and while this measure may not directly implicate genetic factors, family history is an important contributor to outcome. This outcome is based on $11 \%$ of the sample coming from homes with a high RHQ index score.

\section{Models of Reading Achievement}

The second aim of this study was to determine the extent that different distal (family history, gender, IQ) and proximal (phonological, orthographic, rapid visual sequencing and perceptions and attitudes) could predict the different reading skills measured. In each of the multiple regression analyses, substantial variance was accounted for by the combination of variables. In all cases, greatest variance was accounted for by the addition of phonological, orthographic and rapid visual sequencing measures, with the phonological measure producing the strongest unique

relationship to each of the reading measures. The addition of children's perceptions of 
their reading competence, difficulties with reading and attitudes toward reading, added significant additional variance to outcome. Perceptions of competence and difficulty with reading produced the stronger effects for word identification and spelling, with attitudes and perceptions both contributing to comprehension score.

In all analyses, the phonological processing measure continued to account for significant unique variance in word recognition, spelling and comprehension after all other variables were considered. This finding is consistent with previous research that shows the importance of phonological analysis skills to reading performance (see Snowling, 2000; Vellutino et al., 2004). In the present study, a group measure of phonological processing was used. Children were required to silently "sound out" three non-words, and were required to circle the non-word that sounded like a real word. While arguably less variance was accounted for than when more individual measures of non-word decoding are used, this measure has been shown to have adequate sensitivity (McBride et al., 1993).

Based on the standardised regression coefficients for orthographic processing stronger impacts on outcome were for spelling and comprehension, over word identification. The impact on spelling is consistent with the nature of the task, which required children to determine which of two words, which sounded the same (so controlled for phonological skills), was spelled correctly. McBride et al. (1993) found that performance on a similar task was also a significant predictor of comprehension score when the influence of other cognitive variables and the home literacy environment was controlled. Talcott et al. (2000), when using a small group of children of a similar age, found a strong relationship between performance on a similar measure and word identification and spelling performance. This shows that knowledge of orthography as well as phonological skills makes significant 
contributions to outcome when the English language is considered for the age group examined.

After the impact of phonological and orthographic processing was considered, rapid visual sequencing also produced significant independent contributions to word identification, spelling and comprehension. The strongest effects were found for word recognition and spelling. This is consistent with the argument that rapid visual sequencing accounts for variance specifically at the word reading level. Using a similar age-group, Eden et al. (1995) found significant between group effects for reading disabled and control children on a similar task. About $16 \%$ of the variance in word reading skills was accounted for by children's performance on the rapid visual sequencing task, which was similar to that found in adults after ability and memory was accounted for (Conlon et al., 2004). In this study less variance was accounted for, however, a normative sample was used here, rather than participants from the opposite ends of the reading skill continuum.

In the present study, the interval between stimulus presentations was shorter than that used in previous studies. This produced some floor effects for all participants when larger stimulus sequences were presented, suggesting that this sort of rapid sequencing skill is still developing. Visser et al (2004) also found that children were unable to disengage attention from a single stimulus and attend to a second stimulus as quickly as adults. These data support Hari and Renvall's (2001) theory of sluggish attentional shifting among poorer readers with presentation of visually presented symbols. It remains to be determined whether poorer performance on this task is the result of poor reading skills (lack of experience) or a cause of reading difficulties.

In all analyses, children's perceptions of their own reading competence and the level of difficulty they reported with reading explained a significant portion of the variance for the different reading skills. When word recognition and spelling were 
evaluated children's perceptions of competence and ease with reading made a significant contribution to outcome. With comprehension both perceptions of competence and attitude to reading made a significant contribution to outcome. There is a growing consensus that a child's perceptions of him or herself as readers are related to their actual reading achievement (Chapman \& Tunmer, 1995). However, controversies exist concerning their causal ordering. For example, applying a skills developmental perspective, Chapman and Tunmer (1995) point out that reading achievement predicts reading self-perceptions. More specifically, children's reading self-perceptions form and develop in response to how well they master important reading skills and their experiences of ease or difficulty with reading material (Chapman \& Tunmer, 2003).

Contrary to the skills developmental perspective, others argue for a selfenhancement model (Gerber, Ginsberg, \& Reiff, 1992; Marsh, 1990). That is, positive reading self-perceptions are a necessary prerequisite for reading achievement. Gerber et al. (1992) have postulated that motivation represents one mechanism through which reading self-perceptions enhance reading achievement. More specifically, they hypothesized that the motivational influence of reading self-concept on reading achievement occurs through mediating variables, such as the intention to learn, the amount of effort expended during reading, and the degree of persistence in pursuing text comprehension. The motivational consequences of reading self-concept are that children with more positive reading self perceptions will engage more in reading, invest greater effort, and will persist when difficulties arise in their reading (Baker $\&$ Wigfield, 1999; Bishop \& Snowling, 2004; Obach, 2003). There is support for both sides, suggesting that reading self-concept and reading achievement are dynamically interactive and reciprocal (Hamechek, 1995). The reciprocal effect demonstrates the importance placed on reading self-concept as a means of facilitating desirable reading 
outcomes, as well as the importance of the role of reading achievement in developing a positive reading self-concept (Hamachek, 1995). With 12 year olds, it also makes a significant contribution to reading outcome, after the more traditional variables have been accounted for in the model.

The limitation of the current study is that it is cross-sectional only. Continued data collection on this group in future years will allow us to make causal statements concerning the impact of the different combination of variables used, as the adolescent years progress.

\section{Conclusion}

Based on these analyses, family history contributes significantly to the explanation of orthographic processing and children's perception of competence and difficulty in reading, but not rapid visual sequencing or phonological processing. The RHQ index could be a useful additional tool when explaining children's reading performance. The sample used here was both normative and older than others that have used a measure of family history to determine risk. Based on the overall findings, investigation of both family history and children's perceptions of reading competence are important additional variables that should be included when considering the factors associated with reading performance. 


\section{References}

Amitay, S., Ben-Yehudah, G., Banai, K., Ahissar, M. (2002). Disabled readers suffer from visual and auditory impairments but not from a specific magnocellular deficit. Brain, 125, 2272-2285

Bishop, D.V.M. \& Snowling, M.J. (2004). Developmental dyslexia and specific language impairment: same or different. Psychological Bulletin, 130, 858-886

Booth, J.R., Perfetti, C.A., MacWhinney, B., \& Hunt, S.B. (2000). The association of rapid temporal perception with orthographic and phonological processing in children and adults with reading impairments. Scientific Studies of Reading, 4, 101-132

Bouffard, T., Marcoux, M., Vezeau, C., \& Bordeleau, R. (2003). Changes in selfperceptions of competence and intrinsic motivation among elementary school children. Journal of Educational Psychology, 73, 171-182

Castles, A., \& Coltheart, M. (1993). Varieties of developmental dyslexia. Cognition, 47, $149-180$

Castles, A., Datta, H., Gayan, J. \& Olson, R. K. (1999). Varieties of developmental reading disorder: genetic and environmental influences. Journal of Experimental Child Psychology, 72, 73-94

Chapman, J., \& Tumner, W. (1995). Development of young children's reading selfconcepts. An examination of emerging subcomponents and their relationship with reading achievement. Journal of Educational Psychology, 87, 154-167

Compton, D. L. (2002). The relationship among phonological processing, orthographic processing, and lexical development in children with reading disabilities. The Journal of Special Education, 35, 201-211

Conlon, E., Sanders, M., \& Zapart, S. (2004). Temporal processing in poor adult readers, Neuropsychologia, 42, 142-157 
Cunningham, A.E. \& Stanovich, K.E. (1997). Early reading acquisition and its relation to reading experience and ability 10 years later, Developmental Psychology, 33, 934-945

Cunningham, A.E., Perry, K.E., \& Stanovich, K.E. (2001). Converging evidence for the concept of orthographic processing. Reading and Writing: An Interdisciplinary Journal, 14, 549-568

Davis, C. J., Knopik, V. S., Wadsworth, S. J., \& DeFries, J. C. (2000). Self-reported reading problems in parents of twins with reading difficulties. Twin research, 3 , $88-91$

DeFries, J. C., Alarcon, M., \& Olson, R. K. (1997). Genetics and dyslexia: Developmental differences in the etiologies of reading and spelling deficits. In Hulme, C. and Snowling, M. (Eds.), Dyslexia: Biological bases identification and intervention, pp. 20-37. Whurr Publishing: London.

Demb, J.B., Boynton, G.M. \& Heeger, D.J. (1998). Functional magnetic resonance imaging of early visual pathways in dyslexia. Journal of Neuroscience, 18, 6939-6951

Dweck, C. (1999). Self-theories: Their role in motivation, personality, and development. Philadelphia, PA: Psychology Press.

Eccles, J. S., \& Wigfield, A. (2002). Motivational beliefs, values and goals. Annual Review of Psychology, 53, 109-132.

Elbro, C., Borstrom, I., \& Petersen, D.K. (1998). Predicting dyslexia from kindergarten: The importance of distinctiveness of phonological representations of lexical items. Reading Research Quarterly, 33, 36-60

Finucci, J.M., Whitehouse, C.C., Isaacs, S.D., \& Childs, B. (1984). Derivation and validation of a quantitative definition of specific reading disability for adults. Developmental Medicine and Child Neurology, 26, 143-153 
Fletcher, J. M., Foorman, B. R., Boudousquie, A., Barnes, M. A., Schatschneider, C., \& Francis, D. J. (2002). Assessment of reading and learning disabilities. A research-based intervention-orientated approach. Journal of School Psychology, $40,27-63$

Fletcher, J.M., Shaywitz, S.E., Shankweiler, D.P., Katz, L., Liberman, I.Y., Stuebing, K.K., Francis, D.J., Fowler, A.E., Shaywitz, B.A. (1994). Cognitive profiles of reading disability: comparisons of discrepancy and low achievement definitions. Journal of Educational Psychology, 86, 6-23

Gallagher, A., Frith, U., \& Snowling, M.J. (2000). Precursors of literacy delay among children at genetic risk of dyslexia. Journal of Child Psychology and Psychiatry, 41, 203-213

Gayan, J. \& Olson R. K. (2001). Genetic and environmental influences on orthographic and phonological skills in children with reading disabilities. Developmental Neuropsychology, 20, 487-511

Gilger, J.W. (1992). Using self-report and parental-report survey data to assess past and present academic achievement of adults and children. Journal of Applied Developmental Psychology, 13, 235-256

Gilger, J. W., Pennington, B. F \& DeFries, J. C. (1991). Risk of reading disability as a function of parental history in three family studies. Reading and Writing, 3, 205-217

Gregory, R. (2000). Psychological Testing, USA: Allyn \& Bacon, Inc

Guay, F., Marsh, H. W., \& Boivin, M. (2003). Academic self-concept and academic achievement: Developmental perspective on their causal ordering. Journal of Educational Psychology, 95, 124-136 
Hamachek, D. (1995). Self-concept and school achievement: Interaction dynamics and a tool for assessing the self-concept component. Journal of Counselling and Development, 95, 419-426.

Hari R. \& Renvall H. (2001). Impaired processing of rapid stimulus sequences in dyslexia. Trends in Cognitive Science, 5, 525-532

Hari, R., Valta, M. \& Uutela, K. (1999). Prolonged Attentional Dwell Time in Dyslexic Adults. Neuroscience Letters, 271, 202-204

Hulme and M. Snowling (Eds), Dyslexia: Biological bases identification and intervention, pp. 20-37. Whurr Publishing: London.

Jacobs, J., Lanza, S., Osgood, D., Eccles, J., \& Wigfield, A. (2002). Changes in children's self-competence and values: Gender and domain differences across grades one through twelve. Child Development, 73, 509-527

Lepola, J., Salonen, P., \& Vauras, M. (2000). The development of motivational orientations as a function of divergent reading careers form pre-school to the second grade. Learning and Instruction, 10, 153-177

Livingstone M., Rosen G., Drislane F., \& Galaburda A. (1991). Physiological and anatomical evidence for a magnocellular defect in developmental dyslexia. Proceedings of the National Academy of Science, 88, 7943-7947

Lefly, D. L., \& Pennington, B. F. (2000). Reliability and validity of the adult reading history questionnaire. Journal of Learning Disabilities, 33, 286-296

Leslie, L \& Allen, L., (1999). Factors that predict success in early literacy intervention projects. Reading Research Quarterly, 39, 72-93

Locke, J.L., Hodgson, J., Macaruso, P., Roberts, J., Lambrecht-Smith, S., \& Guttentag, C. (1997). The development of developmental dyslexia. In C. Hulme \& M. J. Snowling (eds), Dyslexia Biology, Cognition and Intervention London: Whurr, pp.72-96 
Maqsud, M. (1997). Effects of metacognitive strategies and non-verbal reasoning ability on academic achievement of high school pupils. Educational Psychology, 17, 378-402

McBride-Chang, C., Manis, F.R., Seidenberg, M.S., Custodia, R.G., Doi, L.M. (1993). Print exposure as a predictor of word reading and reading comprehension in disabled and non-disabled readers. Journal of Educational Psychology, 85 (2), 230-238

Molfese, V. J., Modglin, A. A., \&Molfese, D. L. (2003). Newborn and preschool predictors of second-grade reading scores: An evaluation of categorical and continuous scores. Journal of Learning Disabilities, 34, 545-554

Naglieri, J.( 2001). Do ability and reading achievement correlate? Journal of Learning Disabilities, 34, 304-306

Nation, K., \& Snowling, M. J. (2004). Beyond phonological skills: Broader language skills contribute to the development of reading. Journal of Research in Reading, $27,342-356$.

Olson, R. K. (2002). Dyslexia: nature and nurture. Dyslexia, 8, 143-159

Olson, R., \& Datta, H. (2002). Visual-temporal processing in reading-disabled and normal twins. Reading and Writing: An Interdisciplinary Journal, 15, 127-149

Olson, R., Forsberg, H., Wise, B., \& Rack, J. (1994). Measurement of word recognition, orthographic and phonological skills. In G. R Lyon (Ed.), Frames for the Assessment of Learning Disabilities: New Views on Measurement Issues, pp. 243-277. Paul H. Brookes Publishing Co: Baltimore

Pennington, B.F., \& Lefly, D.L. (2001). Early reading development in children at family risk of dyslexia. Child Development, 72, 816-833 
Pugh, K. R., Mencl., W. E., Jenner, A. R., Katz, L., Frost, S. J., Lee, J. R., Shaywitz, S. E., Shaywitz, B. A. (2001). Neurobiological studies of reading and reading disability. Journal of Communication Disorders, 34, 479-492

Raven, J., Raven, J., \& Court, J. (2000). Standard progressive matrices. Oxford, UK: Oxford University Press.

Samuelsson, S., \& Lundberg, I. (2003). The impact of environmental factors on components of reading and dyslexia. Annals of Dyslexia, 53, 210-212

Scarborough, H.S. (1989). Prediction of reading disability from familial and individual differences. Journal of Educational Psychology, 81, 101-108

Skinner, E. A., Zimmer-Gembeck, M. J., \& Connell, J. P. (1998). Individual differences and the development of perceived control. Monographs of the Society of Research in Child Development, 63 (2-3, Whole No. 204).

Snowling M. (2000). Dyslexia. Oxford: Blackwell

Snowling, M.J., Gallagher, A., and Frith, U. (2003). Family risk of dyslexia is continuous: Individual differences in the precursors of reading skills. Child Development, 74, 358-373

Stanovich, K. E., Siegel, L. S. (1994). Phenotypic performance profile of reading disabled children: A regression-based test of phonological-core variabledifference model. Journal of Educational Psychology, 86, 24-53

Stanovich, K. E., Siegel, L. S., Gottardo, A., (1997). Converging evidence of phonological and surface subtypes of reading disability. Journal of Educational Psychology, 89, 114-127

Talcott J., Witton C., McLean M., Hansen P., Rees A., Green G., \& Stein J. (2000) Dynamic sensory sensitivity and children's word decoding skills. Proceedings of the National Academy of Science, 97, 2952-2957 
Talcott J. Witton C. Hebb G. Stoodley C. Westwood E. France S. Hansen P. \& Stein J. (2002) On the relationship between dynamic visual and auditory processing and literacy skills: Results from a large primary-school study. Dyslexia, 8, 204225

Tiu, R. D., Wadsworth, S. J., Olson, R. K., \& DeFries, J. C. (2004). Causal models of reading disability: a twin study. Twin Research, 7, 275-283

Torgeson, J. K., Wagner, R. K., Rashotte, C. A. (1997). Prevention and Remediation of Severe Reading Disabilities: Keeping the End in Mind. Scientific Studies of Reading, 1, 217-234

Treiman, R. (2000). The foundations of literacy. Current Directions in Psychological Science, 9, 89-92.

Vellutino, F., Fletcher, J., Snowling, M., \& Scanlon, D. (2004). Specific reading disability (dyslexia): What we have learned in the past four decades? Journal of Child Psychology and Psychiatry, 45, 2-40

Visser, T.A.W, Boden, C., \& Giaschi, D.E. (2004). Children with dyslexia: evidence for visual attention deficits in perception of rapid sequences of objects. Vision Research, 44, 2521-2535

Wigfield, A., Eccles, J., Arbreton, H., Freedman-Doan, A., \& Blumenfeld, P. (1997). Changes in children's competence beliefs and subjective task values across the elementary school years: A 3-year study. Journal of Educational Psychology, $89,451-469$

Wilkinson, G. (1993). The wide range achievement test. Delaware: Wide Range Inc. 